Acta Cryst. (2002). A58 (Supplement), C52

\section{ABSORPTION- AND PHASE-CONTRAST MICROTOMOGRAPHY AT} HASYLAB / DESY

F. Beckmann $^{1}$ T. Lippmann ${ }^{2}$ U. Bonse ${ }^{3}$

${ }^{1}$ Hamburger Synchrotronstrahlungslabor HASYLAB at Deutsches ElektronenSynchrotron DESY, Notkestrasse 85, 22603 Hamburg, Germany ${ }^{2}$ GKSSForschungszentrum Geesthacht GmbH, Max-Planck-Strasse, 21502 Geesthacht, Germany ${ }^{3}$ Department of Physics, University of Dortmund, OttoHahn-Strasse 4, 44221 Dortmund, Germany

Microtomography using synchrotron radiation has become a valuable tool for the 3-d investigation of samples in the fields of e.g. Medicine, biology and material science. At HASYLAB at DESY absorption-contrast microtomography is applied in user mode at three different beamlines BW2, $\mathrm{W} 2$ and BW5 covering the energy range from $4 \mathrm{keV}$ to $150 \mathrm{keV}$. Furthermore intererometric phase-contrast microtomography was developed and applied using 12, 20, 24 and $70 \mathrm{keV}$. Furthermore different scanning techniques were developed and applied to larger samples up to $24 \mathrm{~mm}$ in diameter and $40 \mathrm{~mm}$ in height. The experimental setup originally developed at the University of Dortmund, Germany and the improvements made at Hasylab to provide for a user experiment for absorption-contrast microtomography will be described. Several examples will demonstrate the practical application of the current system as a user experiment for performing continuous tomographical scans.

\section{Keywords: SYNCHROTRON RADIATION}

Acta Cryst. (2002). A58 (Supplement), C52

HIGH-RESOLUTION HARD X-RAY PHASE-CONTRAST

MICROSCOPE FOR OBSERVING TRANSPARENT BIOLOGICAL SPECIMENS

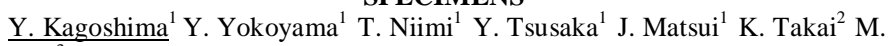
Aino $^{3}$

${ }^{1}$ Himeji Institute of Technology Faculty of Science 3-2-1 Kouto KAMIGORI HYOGO 678-1297 JAPAN ${ }^{2}$ Japan Synchrotron Radiation Research Institute ${ }^{3}$ Hyogo Prefectual Agricultural Institute

A hard X-ray imaging transmission microscope has been in development using an X-ray beam from an undulator in SPring-8 $(1,2)$. It uses a Fresnel phase zone plate made of tantalum as its X-ray lens. The diameter and the outermost zone width of the latest phase zone plate are $1 \mathrm{~mm}$ and $50 \mathrm{~nm}$, respectively. The microscope has achieved the high spatial resolution capable of imaging as fine as $100 \mathrm{~nm}$ line-and-space patterns at the photon energy of $10 \mathrm{keV}$ (3). The Zernike's phase-contrast method has been implemented to the microscope with phase plates made of gold. The photon energy was tuned to $12 \mathrm{keV}$ near the L3 absorption edge of gold $(11.9 \mathrm{keV})$ in order to increase the phase contrast. To demonstrate its capability, small polystyrene $\left(\left[\mathrm{CH}\left(\mathrm{C}_{6} \mathrm{H}_{6}\right) \mathrm{CH}_{2}\right]_{\mathrm{n}}, \rho=1.1 \mathrm{~g} / \mathrm{cm}^{3}\right)$ particles of $7 \mu \mathrm{m}$ in diameter were imaged clearly in the opposite contrast (positive and negative contrast) with phase plates to shift the phase of the central order of the Fourier spectra in the back focal plane of the objective by one-quarter and three-quarters of a period, while the conventional absorption imaging showed little contrast. Further, diatoms and conidia were also imaged with good contrast even in water. The phase-contrast microscope may open a way to observe thick biological specimens in their natural living state. References

(1) Y. Kagoshima et al., Jpn. J. Appl. Phys. 39 (2000) L433.

(2) Y. Kagoshima et al., Jpn. J. Appl. Phys. 40 (2001) L1190.

(3) Y. Kagoshima et al., Jpn. J. Appl. Phys. 41 (2002) 412.

Keywords: X-RAY MICROSCOPE PHASE CONTRAST ZONE PLATE
Acta Cryst. (2002). A58 (Supplement), C52

PHASE-SENSITIVE X-RAY IMAGING AT THE SYRMEP BEAMLINE OF ELETTRA

G. Tromba $^{1}$ F. Arfelli ${ }^{2}$ E. Castelli ${ }^{2}$ D. Dreossi ${ }^{2}$ R. Longo ${ }^{2}$ L. Mancini ${ }^{1}$ R.H. Menk $^{1}$ F. Montanari ${ }^{1}$ A. Olivo ${ }^{2}$ S. Pani ${ }^{2}$ L. Rigon $^{2}$ F. Zanini ${ }^{1}$

${ }^{1}$ Sincrotrone Trieste S.S.14 - Km 163.5 Basovizza TRIESTE 34012 ITALY

${ }^{2}$ Department of Physics - Universita' di Trieste

Taking advantage of the high intensity and high spatial coherence of synchrotron radiation, it is possible to investigate the use of phase-sensitive imaging techniques in the hard $\mathrm{X}$-rays region. Actually, in the energy range $15 * 25 \mathrm{keV}$, the phase shift is up to 1000 times more sensitive to variation of the structure and composition of soft biological tissues if compared with absorption. Therefore it is possible to reveal phase effects even if the absorption is negligible.

At Elettra a research program dedicated to medical imaging is carried out at the SYRMEP beamline where the use of the PHase Contrast radiology (PHC) and the Diffraction Enhanced Imaging (DEI) techniques, in various contexts of diagnostic radiology, are studied. Recently the same approaches have been applied also to other fields of investigation, in material science and in the imaging of biomaterials.

On account of SYRMEP is a bending magnet beamline, with a source dimension of approximately $140 \mu \mathrm{m} \times 1100 \mu \mathrm{m}$, nevertheless the obtained results show the efficacy of the phase-sensitive imaging with respect of conventional absorption radiography. Regarding the applications to diagnostic radiology, the PHC and DEI techniques bring a significant improvement in the contrast resolution and in the visibility of details with no increase of the delivered dose

Keywords: PHASE IMAGING, PHASE CONTRAST RADIOLOGY, DIFFRACTION ENHANCED IMAGING
Acta Cryst. (2002). A58 (Supplement), C52

DEVELOPMENT OF X-RAY DARK FIELD IMAGING

M. Ando ${ }^{1,2}$ H. Sugiyama ${ }^{1,2}$ A. Maksimenko ${ }^{2}$ W. Pattanasiriwisawa ${ }^{2}$ K. Hyodo $^{1,3}$ E. Rubenstein ${ }^{4}$ J. Roberson ${ }^{5}$ Y. Tanaka ${ }^{6}$

${ }^{1}$ Photon Factory, KEK Oho 1-1, TSUKUBA, IBARAKI 305-0074 JAPAN

${ }^{2}$ Dept Photo-Science, GUAS ${ }^{3}$ Dept Structure Studies, GUAS ${ }^{4}$ Medical Dept, Stanford University ${ }^{5}$ California Ear Institute ${ }^{6}$ Advanced Material Science

We would like to report an $\mathrm{X}$ ray optics capable of dark field imaging 'Owl' comprising a Bragg case asymmetric monochromator and a monolithic X-ray optics housing a collimator $\mathrm{C}$ and an analyzer $\mathrm{A}$ that can select only the refracted light by 4,4,0 diffraction and the crystals $\mathrm{C}$ and A with $1.08 \mathrm{~mm}$ thickness. Their angular width of diffraction was $0.3 \mathrm{mrad}$ at X-ray energy of $35 \mathrm{keV}$. It has been proven that one can obtain a forward diffracted beam which corresponds to the dark field imaging and the other a diffracted one corresponding to the bright field or vice versa depending on the specified thickness of the analyzer. Images due to refraction contrast in the dark field imaging are clearly shown. In this talk successful design and test of this X-ray optics and its preliminary applications are described in details. Also I would like to talk about another X-ray optics 'Trinity' capable of viewing three kinds of contrast, refraction, phase interference and absorption, which has been successfully in operation.

References:

[1] M. Ando, H. Sugiyama, A. Maksimenko, W. Pattansiriwisawa, K. Hyodo and Zhang X.: Jpn. J. Appl. Phys. 40 (2001) L844.

[2] M. Ando, H. Sugiyama, Zhang X., K. Hyodo, A. Maksimenko and W. Pattansiriwisawa: Jpn. J. Appl. Phys. 40 (2001) L298.

[3] M. Ando, J. Chen, K. Hyodo, K. Mori, H. Sugiyama, D. Xian and Zhang X.: Jpn. J. Appl. Phys. 39 (2000) L1009.

Keywords: X-RAY OPTICS, SILICON, X-RAY DARK FIELD IMAGING 